
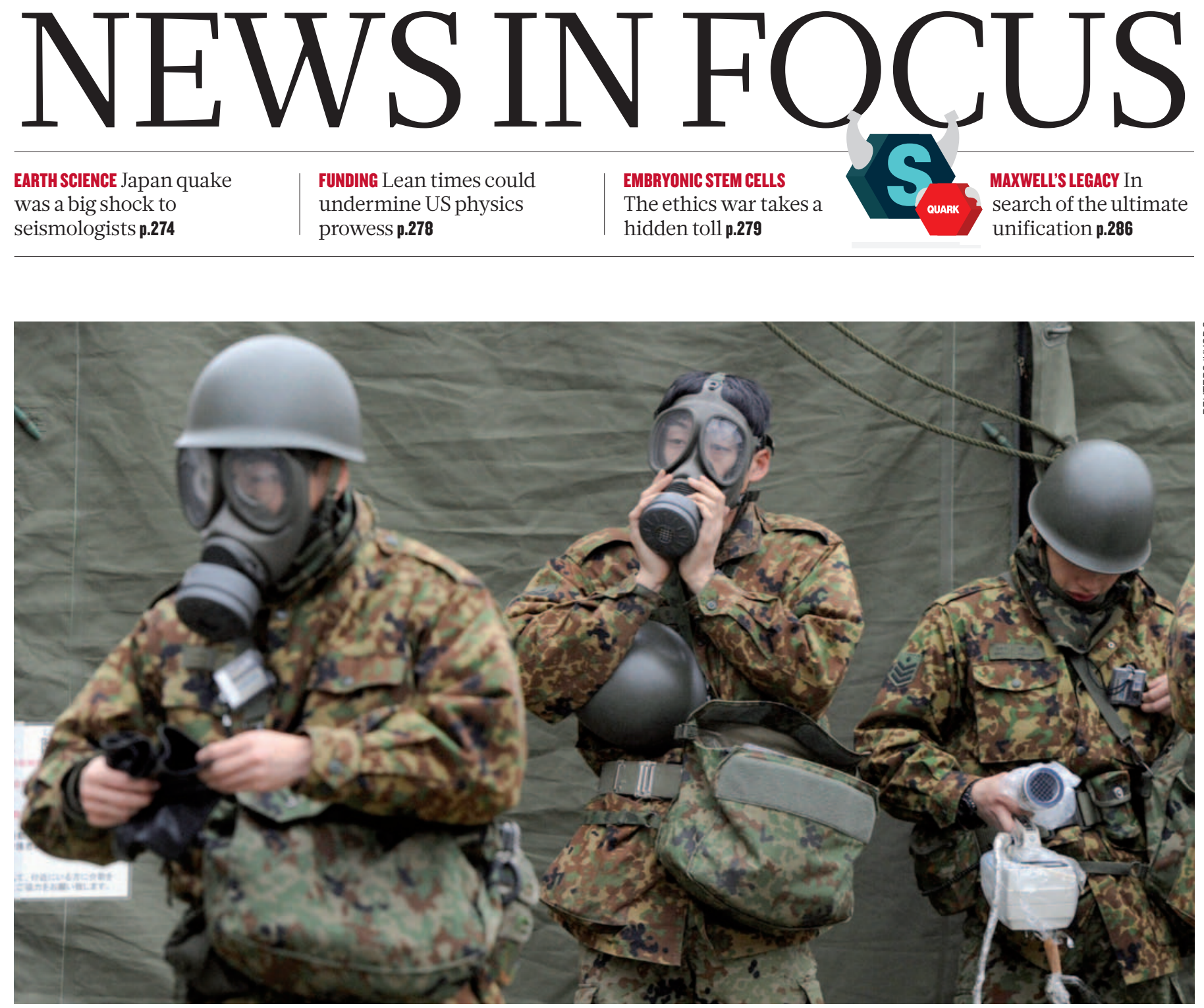

Members of the Japanese military have already begun a clean-up operation in areas affected by radiation from the Fukushima Daiichi power station.

\title{
Quake sparks nuclear crisis
}

\section{Explosions at a tsunami-hit plant will knock public confidence and the industry worldwide.}

\section{BY GEOFF BRUMFIEL IN LONDON AND DAVID CYRANOSKI IN TOKYO}

The magnitude-9.0 earthquake and resulting tsunami that struck Japan on

11 March have left thousands dead and many more homeless.

But the farthest-reaching consequence of the devastating natural disaster is the ongoing nuclear emergency at the Fukushima Daiichi nuclear power station. As Nature went to press, plant operators were struggling to cope with multiple reactors that had lost the ability to cool themselves. Three units operating at the time of the quake seem to have suffered a partial meltdown, and some spent fuel stored at the plant has been exposed, releasing radiation.

The situation could still worsen. But scientists and engineers who have sought a revival of nuclear power for the past decade acknowledge that the accident, the worst since the Chernobyl disaster in 1986, is already a devastating blow for the technology. "It will be bad; I mean I don't think there's any point in pretending," says Robin Grimes, director of the Centre for Nuclear Engineering at Imperial College London, and an advocate of nuclear power.

The crisis began at 2:46 p.m. local time on Friday, when the massive quake struck (see 'Seismic puzzle'). Nuclear reactors at four plants in the region immediately inserted control rods into their cores, effectively shutting them down (see 'Inside the core'). However, even after the shutdown, the decay of radioactive elements in the cores continued to pump out heat. The electric cooling pumps had lost power from the grid, but back-up diesel generators kicked into action, and ultra-pure cooling water continued to circulate through the cores.

Roughly half an hour later, however, a wall of water breached the sea wall protecting the Fukushima Daiichi plant - one of the closest to the epicentre - and struck the main back-up generators. "The problem wasn't the earthquake, but the tsunami," says Mitsuru 


\section{SEISMIC PUZZLE}

\section{Giant shock rattles ideas about quake behaviour}

"This earthquake is a lesson in humility," says Emile Okal, a geophysicist at Northwestern University in Evanston, Illinois, who studies great earthquakes and tsunamis. Few experts had thought that the seismic zone near Sendai, Japan, was capable of producing earthquakes anywhere near as powerful as the magnitude- 9.0 shock on 11 March, the largest on record in Japan. Okal and his colleagues want to understand why the event was so much stronger than many people expected — and what it means for seismic risks in Japan and elsewhere around the globe.

The quake happened along a seam in the planet's surface where the Pacific Ocean floor is diving beneath the tectonic plate carrying northern Japan (see 'Collision zone'). That process of subduction triggers the largest earthquakes in the world, such as the magnitude-9.5 Chilean quake in 1960 and the magnitude-9.1 Sumatran quake in 2004. But geophysicists had thought that great subduction-zone earthquakes happened only where younger oceanic crust scrapes its way into the mantle. Older crust, which is cooler and denser, was thought to slide much more readily downward, triggering smaller quakes. And the ocean crust off the northeast part of Japan, having formed about 140 million years ago, is about as old as it can get.

The history of the Sendai region seemed to support that idea. "There has been seismicity but not really great-earthquake seismicity," says Hiroo Kanamori, a seismologist at the California Institute of Technology in Pasadena. In the past few centuries, the subduction zone off the coast of Sendai has generated earthquakes of up to magnitude 8 or so, but nothing as powerful as a 9 , which releases 30 times more energy.

Given that history, seismologists in Japan did not consider great earthquakes to be a threat to the Sendai area. And although that region was one of Japan's bestprepared for tsunamis, the high sea walls along much of the coast were built to stop waves far smaller than the 13-15-metretall giants that battered the coastline, causing most of the damage and triggering a nuclear crisis.

But some clues suggested that the Sendai region might be capable of greater violence. The giant Sumatran earthquake $\rightarrow$ NATURE.COM Read about the largest earthquake ever recorded at: go.nature.com/hihawf

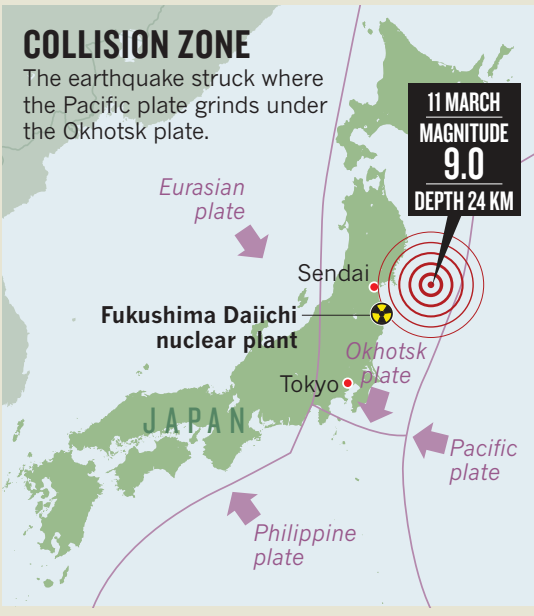

raised questions about the sea-floor-age hypothesis, because the old subducting crust there should have ruled out a shock of that size, says Okal. And recent geodetic studies across Japan showed that the Sendai region is getting squeezed, as in a vice, by pressure from the plate motions. The warping suggested that the Pacific plate was stuck rather than sliding smoothly beneath Japan, straining the crust.

The strain could only be released in earthquakes, and it builds up so quickly that the size and frequency of earthquakes seen in the recent past would not have been enough to release it, says Thomas Heaton, a geophysicist at the California Institute of Technology. It took last week's quake to do the job - and big as it was, it may not have released all the accumulated strain, says Heaton. "There's still a mystery to this place even with the 9."

If the subduction zone near Sendai can produce a great quake, then other areas with similarly old ocean crust might too, says Okal, who says that Tonga and the northeastern Caribbean are regions to look at more closely. Clues to rare, great earthquakes may be hidden there - as it seems they were in Sendai.

The last giant tsunami recorded in Sendai struck in 869. Judging from geological traces of two even older tsunami deposits, Koji Minoura, an Earth scientist at Tohoku University in Sendai, and his colleagues proposed in 2001 that giant waves visit the region about every 800-1,100 years (K. Minoura et al. J. Nat. Disaster Sci. 23, 83-88; 2001). Because the last one came in the ninth century, the researchers wrote, "the possibility of a large tsunami striking the Sendai plain is high". Richard Monastersky
- Uesaka, a nuclear engineer at the University of Tokyo. The flooding is believed to have irrevocably damaged the oil tank and other key parts of the system.

With the cooling system crippled, reactor unit 1 at Daiichi was the first to heat up. Water in the core began to boil off, raising the temperature and pressure inside the massive steel containment vessel. As temperatures soared, the zirconium alloy coating the fuel apparently split or melted, reacting with the steam to produce copious amounts of hydrogen gas.

The pressure was reaching worrisome levels by the afternoon of 12 March, and Tokyo Electric Power Company (TEPCO), which runs the plant, made the bold decision to vent radioactive steam. "There was no other choice," says Masashi Goto, a former engineer at Toshiba who is an expert on the design and testing of the containment vessel. At around 3:30 p.m., shortly after TEPCO announced the venting, an explosion rocked reactor number 1 . This is thought to have been caused by hydrogen from the core. The blast was powerful enough to rip the superstructure of the reactor apart, although the hardened containment vessel appears to have remained intact.

\section{EXTREME MEASURES}

Reactor operators decided to take drastic action to prevent further melting of the fuel and a possible breach of the containment vessel. At 8:20 p.m. they began to flood unit 1 with sea water, effectively ruining the reactor. As an added safety measure, they injected neutronabsorbing boric acid into the core.

Over the next two days, the two other operating reactors at Fukushima Daiichi followed a similar path. On the afternoon of 13 March, more diesel generators at the site shut down, raising fears of overheating at units 2 and 3 . That evening, operators filled unit 3 with sea water and boric acid. The following morning, it too was rocked by what seems to have been a massive hydrogen explosion. Unit 2, meanwhile, reportedly lost almost all of its cooling water, and was filled with sea water on 14 March.

At 6:14 a.m. on $15 \mathrm{March}$, the pressuresuppression pool beneath the containment vessel of unit 2 was rocked by a blast. Uesaka says that, unlike previous explosions, this one was much closer to the reactor core, releasing a higher density of radioactivity and raising fears of damage to the core and the surrounding containment vessel. At around the same time, unit 4 unexpectedly caught fire. The reactor had been shut down for inspection at the time of the earthquake, and it is thought that the fire occurred when old fuel rods, stored in deep pools in the building, became exposed and overheated, releasing explosive hydrogen. Immediately after the explosion and fire, an ominous spike in radiation was detected outside the unit. Radiation monitors at the Daiichi plant briefly picked up radiation in the range of 400 millisieverts per hour, 400 times the legal 
limit and the highest rate since the crisis began.

All three distressed reactors are thought to have at least partly melted down. Barring a full-scale meltdown or another fire in the spent fuel, the danger will subside with each day, as radioactive elements in the fuel decay. But most experts agree that to avert further damage, cooling will need to continue for weeks. The clean-up will take years or even decades.

The situation remained in flux as Nature went to press, but it is clear that the ramifications for the nuclear industry will be enormous worldwide. In Japan itself, critics were already questioning whether the nation's 54 nuclear power reactors were adequately prepared to handle earthquakes, an issue raised in 2007 after a massive quake struck the KashiwazakiKariwa nuclear plant (see Nature 448, 392-393; 2007). Regulators in Japan will no doubt take a hard look at reactor safety in the coming weeks, which could delay the restart of even undamaged plants. Elsewhere in the region, India has decided to 'revisit' its reactor plans.

In Germany, where resistance to nuclear power is strong and vocal, the disaster immediately reopened the acrimonious debate about extending the lives of ageing reactors. In April 2002, lawmakers restricted the working life of power stations to an average of 32 years, but last December the conservative government revised the law, extending the lifespans of power stations by a further 8 years for those built before 1980 and by 14 years for those built after this date. Now the German chancellor, Angela Merkel, has put a three-month moratorium on that extension to allow time to re-evaluate safety. Seven nuclear power stations will be switched off during this period.

Switzerland has similarly put its plans to replace ageing nuclear power stations on ice. The Italian government, however, said that the disaster in Japan will not affect its plans to resume nuclear energy generation, which halted in the wake of the Chernobyl disaster. And Poland's prime minister expressed confidence in the safety of new reactor designs for the country's first nuclear power station.

The political and regulatory effects are likely to be equally far-reaching in the United States. "This disaster serves to highlight both the fragility of nuclear power plants and the potential consequences associated with a radiological release," Congressman Edward Markey (Democrat, Massachusetts) wrote in a letter to the

\section{INSIDE THE CORE}

Fukushima's boiling-water reactors are a fairly common design from the 1970 s. During normal operation, nuclear fuel boils water, creating steam that can run a turbine.
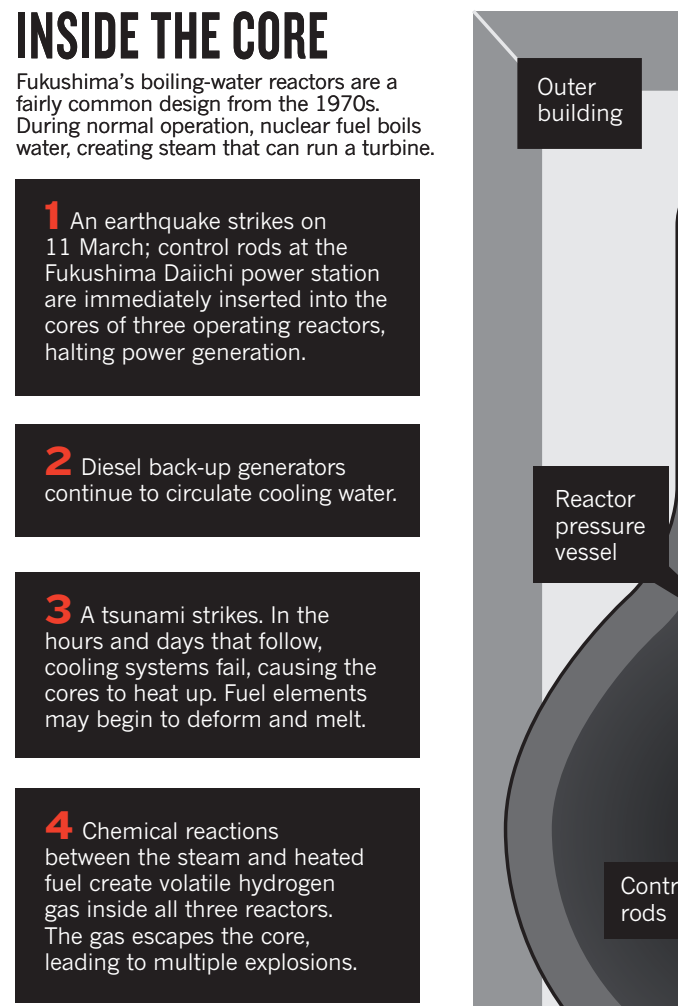

\section{.}

